\title{
LOS DERECHOS \\ DE LOS PARLAMENTARIOS
}

\author{
IGNACIO TORRES MURO \\ Profesor Titular de Derecho Constitucional \\ Universidad Complutense de Madrid
}




\section{SUMARIO}

1. Algunas precisiones previas. 2. Muchas de las facultades de los parlamenTARIOS SON DERECHOS FUNDAMENTALES. 2.1. La insospechada riqueza del artículo 23 CE. 2.2. Facultades o derechos de los parlamentarios. 2.3. La construcción del Tribunal Constitucional. Problemas y alternativas. 2.4. Las facultades que ha reconocido el Tribunal como derechos fundamentales. 3. UN REPASO A LOS REGLAMENTOS. 4. CONCLUSIONES. 


\section{LOS DERECHOS DE LOS PARLAMENTARIOS}

POR

IGNACIO TORRES MURO

Profesor Titular de Derecho Constitucional

Universidad Complutense de Madrid

\section{ALGUNAS PRECISIONES PREVIAS}

No es posible en el espacio del que disponemos profundizar sobre los cambios radicales que ha sufrido la institución parlamentaria desde que se consolidara como alternativa al poder real, en el Continente, a principios del siglo XIX. Pero sí se puede llamar la atención sobre el hecho de que poco tienen que ver los Parlamentos de finales del $\mathrm{XX}$ con aquellas Asambleas de notables.

Poco tiene que ver su posición en el sistema en su conjunto y es muy otra la manera de organizar sus trabajos, sobre todo debido al protagonismo de los partidos politicos. Estas transformaciones traen consigo que el papel a representar por el parlamentario sea también distinto, dato que hace necesario que su status jurídico, el conjunto de normas que regulan sus derechos $y$ deberes, difiera radicalmente del tradicional.

Nótese que hemos hablado de derechos, tomando así partido de antemano en la posible polémica. Mientras que el Diputado producto del sufragio censitario, que se integra en una Cámara homogénea en la que los debates se producen sobre matices y la pertenencia a posibles grupos es muy flexible, puede sentirse satisfecho con la atribución de facultades, el parlamentario actual, que trabaja integrado en la mayoría o en la minoria, que expresa en la Asamblea los enfrentamientos so- 
ciales fundamentales, que ıu es ya miembro de algo similar a un selecto club sino parte de un Parlamento claramente dividido, este prócer de nuestros días, necesita de verdaderos derechos, entre otras cosas porque sólo cuando disfrute de éstos podrá ejercer eficazmente su función de representación de unos electores que no son ya un pequeño grupo de propietarios con intereses más o menos coincidentes en lo fundamental sino los miembros de una sociedad muy compleja con divisiones frecuentes $y$ en la que, aunque pueda haber acuerdo sobre las reglas del juego, la política se convierte a veces en una batalla muy dura para aprovechar al máximo los recursos cuyo control trae aparejada la detentación del poder.

Por todo ello las teorías clásicas sobre la posición de los parlamentarios resultan inadecuadas para explicar la realidad de nuestros días y hay constituciones como la española de 1978, interpretada en el sentido en el que lo ha hecho el Tribunal Constitucional, en las que este estado de cosas se refleja sobre todo en la consideración de los miembros de las Cámaras como representantes de los ciudadanos, vehículo para que las opiniones de éstos lleguen al órgano legislador $y$ de control. El respeto a los derechos de aquéllos se convierte, por tanto, en un elemento fundamental del régimen político, dado que son portadores de los intereses del pueblo, o de un sector significativo del mismo, y facilitan el derecho a la participación de éste.

En el nuevo contexto las facultades atribuidas a los parlamentarios aparecen como verdaderos derechos públicos subjetivos -algo que la doctrina clásica encabezada por Jellinek negaba terminantemente y que aún hoy no se reconoce de una manera pacífica-con el fin de conseguir mediante este blindaje que no se puedan desatender por las mayorías los intereses de quienes ostentan la representación popular. Ya no estamos ante simples servidores ocasionales del Estado sino ante verdaderos delegados que llevan a las Cámaras la voz de unos grupos sociales con intereses divergentes. Ya no puede hablarse de Asambleas en las que el enfrentamiento mayorías-minorias sea versallesco. Ahora es preciso proteger a estas últimas, facilitando sus iniciativas e impidiendo que puedan frustrarse por las presiones de los grupos que apoyan al Ejecutivo. Para ello no hay mejor técnica, en un Estado de Derecho, que el reconocimiento de verdaderos derechos exigibles ante los tribunales, al menos en el caso de las facultades más importantes para el correcto ejercicio del mandato parlamentario. No es la única, evidentemente, y siempre es necesario para el equilibrio del sistema dejar la protección de algunos de ellos a los órganos de gobierno de las Asambleas, especialmente al Presidente y Mesas. Es cier- 
to, además, que la alternancia en el poder y la crítica política tienen también su importancia a estos efectos, pero no hay por qué renunciar a la judicialización de las relaciones parlamentarias allí donde esto sirva para asegurar que se mantienen abiertas todas las posibilidades de control y limitación del poder que son inherentes a una democracia contemporánea.

Es en este nuevo ambiente en el que se mueven los autores de las construcciones normativas y jurisprudenciales que se han dado en España en los últimos veinte años respecto a los derechos de los parlamentarios. Nos toca ahora comentar las mismas adelantando que no se entienden si no se tienen en cuenta los cambios a los que nos hemos referido con necesaria brevedad. Juzgarlas con las categorías construidas en momentos históricos muy distintos denota un respeto por los clásicos que puede resultar un obstáculo para comprender esas nuevas realidades con las que éstos no se enfrentaron.

\section{MUCHAS DE LAS FACULTADES DE LOS PARLAMENTARIOS SON DERECHOS FUNDAMENTALES}

\subsection{La insospechada riqueza del artículo $23 \mathrm{CE}$}

Antes de entrar en el tema en concreto de los derechos de los parlamentarios es imprescindible hacer una referencia, siquiera breve, a la importancia que ha tenido en nuestra vida constitucional el reconocimiento en la norma suprema de los contenidos en el art. $23 \mathrm{CE}$. Se ha resaltado acertadamente por la doctrina la originalidad de los planteamientos del texto de 1978 en esta materia tanto respecto a nuestra historia como a las experiencias extranjeras ${ }^{1}$ y también que, en palabras de Mancisidor, «cuando se aprobó la Constitución posiblemente nadie estaba en condiciones de prever la trascendencia y el juego que llegaría a desarrollar el artículo $23 n^{2}$.

1 Esther Martín lo expresa diciendo que «ni en el constitucionalismo histórico español ni en las constituciones democráticas del entorno europeo se reconoce un derecho a la participación". En su libro El régimen constitucional del cargo público representativo, Barcelona, 1996, p. 25.

2 En «El derecho de información de los parlamentarios en la jurisprudencia constitucional», que es su aportación a F. PAU I VALL (coord.), Parlamento y Justicia Constitucional, Pamplona, 1997, p. 350. 
Éste «se ha convertido en la puerta que permite entrar al Tribunal Constitucional en dos ámbitos trascendentales del proceso politico: el sistema electoral y el funcionamiento de los órganos representativos ${ }^{3}$, coincidiendo asimismo los diversos autores en que la labor de la jurisprudencia de aquél ha sido decisiva a la hora de "dilatar» el contenido del reconocimiento que se preveía en nuestra Carta Magna, especialmente en el caso del apartado 2 del citado artículo 4 .

Cualquier ojeada a los repertorios de sentencias al uso da muestra de cómo, basándose en el aparentemente limitado texto del art. 23 $C E$, el Tribunal ha tomado decisiones de gran trascendencia respecto a las reglas fundamentales del juego político, decisiones que además, como dijo Ballarín en su temprano y acertado comentario, reflejan «en su complejidad, la de la Constitución misma, que, de un lado, recoge los supuestos clásicos del principio representativo $y$, de otro, da entrada jurídicamente a los presupuestos del Estado de partidos” ${ }^{5}$. Es el llamado por Jimenez Campo "enriquecimiento jurisprudencial» del art. 23.2 $\mathrm{CE}^{6}$, enriquecimiento que se produce, como de todos es sabido, a partir de dos sentencias de temática municipal, la 5/1983 y la 32/1985, pero que pronto se contagia a otras instituciones representativas.

En aquéllas se dicen cosas tan trascendentes como que el derecho a acceder a los cargos públicos implica también el de permanecer en los mismos y que hay que considerar protegido asimismo el ejercicio de las funciones que de ellos se derivan, sin que pueda desfigurarse el status de éstos hasta el punto de hacerlo irreconocible. En ambos casos nos encontramos con tesis perfectamente aplicables al ámbito parlamentario a pesar de su origen y que hay que tener siempre en cuenta a la hora de explayarse sobre los derechos de los diputados y senadores.

Basta, por ahora, sin embargo, a nuestros fines, con esta llamada de atención sobre la riqueza del artículo $23 \mathrm{CE}$ que ha provocado unos desarrollos muy importantes, y no sólo en la vida de nuestras 1993, p. 14.

3 E. Fossas Espadaler, El derecho de acceso a los cargos públicos, Madrid,

4 Usan la expresión Fossas, en op. cit. en nota 3, p. 14, y MARTín, en op. cit. en nota 1, p. 74.

5 En su artículo El derecho de acceso a los cargos y funciones públicas, Poder Judicial n. ${ }^{\circ} 5$ (1987), p. 59.

6 En Sobre los derechos fundamentales de los parlamentarios, publicado en F. PAU I VALL (coord.), op. cit. en nota 2, p. 219; y también en AA.VV., Estudios de Derecho constitucional y de Ciencia Política. Homenaje al profesor Rodrigo Fernández-Carvajal, Murcia, 1997, tomo I, p. 412. 
Asambleas. Es en el contexto del mismo en donde se produce la construcción jurisprudencial en la que los parlamentarios aparecen dotados de verdaderos derechos fundamentales frente al órgano del que forman parte, construcción de la que nos ocupamos a continuación.

\subsection{Facultades o derechos de los parlamentarios}

La primera gran pregunta a la que hay que responder para abordar directamente el problema que nos ocupa es la de cuál es la naturaleza jurídica de los poderes que a los parlamentarios atribuyen las diversas normas que regulan sus actividades. La alternativa entre competencia y derecho subjetivo, que apuntó en su momento Pablo Lucas Murillo?, se plantea desde el momento en que es posible entender de muy diversas maneras las relaciones de las Asambleas legislativas con sus miembros.

La más clásica es la representada por G. Jellinek, que afirmó rotundamente en su momento que "los así llamados derechos de los diputados en tanto que miembros de la Cámara no son pretensiones jurídicas individuales, sino competencias de órganos estatales". Para este autor la violación de las normas reglamentarias no lo sería «de un derecho subjetivo, sino infracción de una norma jurídica, ofensa al Estado en su ordenamiento, no ofensa a un individuo" ${ }^{8}$. En esta línea se encuentran también representantes de la doctrina alemana más actual que señalan que, aunque el reglamento hable de derechos del miembro del Bundestag, "en cuanto a su naturaleza jurídica...no se trata de derechos públicos subjetivos, particularmente no de derechos fundamentales, sino de competencias jurídicopúblicas $"{ }^{9}$ y su lesión no puede remediarse por la vía del recurso de amparo sino por la del conflicto entre órganos.

7 En El Estatuto de los parlamentarios, en A. FIgueroa y J. C. DA Silva (coords.), Parlamento y Derecho, Vitoria, 1991, p. 63.

8 En su obra sobre los derechos públicos subjetivos. Hemos manejado la edición italiana que hay en el Centro de Estudios Constitucionales, dado que los cuatro ejemplares de las ediciones alemana e italiana que conservaba la biblioteca de la Facultad de Derecho de la Universidad Complutense han "desaparecido en combate». La cita está tomada de G. JeluneK, Sistema dei Diritti pubblici subbietivi, Milán, 1912, pp. 185-186.

9 H. J. SCHREINER, Geschäftsordnungsrechtliche Befugnisse des Abgeordneten, en Schneider y ZeH (Hg.), Parlamentsrecht und Parlamentspraxis in der Bundesrepublik Deutschland, Berlín-Nueva York, 1989, p. 593. 
En tan ilustre compañía se encuentra en España la profesora Biglino que se ha mostrado muy severa con la construcción del Tribunal Constitucional, hecha a partir de la sentencia 161/1988, en la que se habla de derechos fundamentales de los parlamentarios al referirse a muchas de sus atribuciones. La crítica se contiene en un agudo artículo ${ }^{10}$ en el que se argumenta, entre otras cosas, que aquélla wha conducido a resultados contradictorios y deja además abiertos numerosos interrogantes" ", que "constituye un serio obstáculo para la correcta comprensión de los distintos elementos que integran el acceso a los cargos públicos...(y)...no sirve para explicar las características que, hoy en día, rodean al ejercicio de la función parlamentaria» ${ }^{12}$, y que "resulta difícilmente compatible con el papel instrumental que dichas facultades adquieren en el desarrollo de la actividad de las Cámaras» ${ }^{13}$. Para esta autora, en suma, «definir las facultades de los parlamentarios como atribuciones es más adecuado a la Constitución que concebirlas como derechos fundamentales" ${ }^{14}$.

El debate sin embargo permanece abierto y en él participan otros autores que mantienen una línea diferente, más dispuesta a reconocer a los parlamentarios verdaderos derechos. Así Santschy afirma que "los derechos y deberes resultantes del status de diputado no son derechos del Estado, ni competencias del parlamento, sino garantías y obligaciones conferidas al parlamentario por la Constitución", que éstos «tienen para el diputado la misma función que los derechos fundamentales...para los particulares. Son esencialmente medios de defensa contra la actividad estatal y por tanto su respeto se impone a todos los órganos del Estado", y que "al igual que el individuo, el diputado no es un órgano del Estado. No está dotado de competencias cuyo ejercicio sea obligatorio, sino que dispone de derechos y deberes de los que puede hacer uso según su conciencia» ${ }^{15}$.

En España el autor más abierto a reconocer la existencia de verdaderos derechos de los parlamentarios es García Roca que encuentra su justificación «en que existe un indudable interés general, que el de-

10 Nos referimos a "Las facultades de los parlamentarios ¿son derechos fundamentales?", en Revista de las Cortes Generales, n. 30 (1993).

Ibidem, p. 65.

lbidem, p. 79.

Ibidem, p. 85.

Ibidem, p. 92.

Le droit parlementaire en Suisse et en Allemagne, Neuchâtel, 1982, pp.

120 y 122. 
recho fundamental tutela, en la configuración democrática de la voluntad política de los órganos del Estado " ${ }^{16}$. Recuerda, por otra parte, con agudeza "que un parlamentario no puede seguir siendo considerado...del mismo modo que en el derecho parlamentario clásico como estrictamente un miembro de la asamblea, es también un representante al que la propia Constitución concede un estatuto de derechos y deberes» 17 y que "algo debe la vida parlamentaria a la existencia de este derecho reactivo del representante: la delimitación de una senda en la que el enfrentamiento entre mayoría y minorías, a la hora de la elaboración de las distintas políticas y del ejercicio de las actividades y funciones que a los Parlamentos constitucionalmente corresponden, no es una patente de corso para una confrontación sin reglas; o cuando menos, sin una, el respeto a los derechos fundamentales de cada representante" ${ }^{18}$. En una línea similar se encuentra Cano Bueso para quien «no está de más remarcar que, en el parlamentarismo actual, las facultades que los Reglamentos de las Cámaras confieren a los Diputados y que integran su status parlamentario, no pueden seguir considerándose únicamente como atributos del órgano»19.

La polémica creemos que debe abordarse teniendo en cuenta las exigencias de las relaciones parlamentario-órgano tal y como se presentan a estas alturas de la evolución de las democracias occidentales. Como ya se dijo, y apuntó en su momento con su acierto habitual Stein, «el problema constitucional más importante del Parlamento consiste en la protección de las minorías" ${ }^{20}$. A resolver el mismo han de aplicarse todos los esfuerzos posibles.

No se da evidentemente una única manera de enfrentarse con él. Hay sistemas, como el británico por ejemplo, en el que todo se confía al libre juego de una vida política gobernada por unas convenciones $y$ reglas de cortesía muy consolidadas que hacen innecesario recurrir a mecanismos más formalizados, convenciones defendidas dentro de la

16 "La difícil noción de cargo público representativo y su función delimitadora de uno de los derechos fundamentales del artículo 23.2 de la Constitución", en Revista de las Cortes Generales, n. 34 (1995), p. 85. De este autor también se lee con aprovechamiento su artículo "El control del Gobierno desde la perspectiva individual del parlamentario (y a la luz del art 23.2 de la Constitución)", en Revista Vasca de Administración Pública, n. 42 (1995), pp. 161 y ss.

17 La difícil noción..., p. 91.

18 Ibidem, p. 99.

19 El "derecho de acceso a la documentación" de los diputados en el ordenamiento parlamentario español, Madrid, 1996, p. 74.

20 Derecho Politico, Madrid, 1973, p. 53. 
Cámara por un Speaker con fuerte conciencia de su papel en la defensa de la posición de todos los miembros de la misma. Este modelo sigue teniendo gran peso, pero quizá sea inexportable y difícil de aplicar en paises en los que dichas tradiciones, derivadas de un funcionamiento tan prolongado de la institución como el que se da en Inglaterra, simplemente no existen. Es la manera de ver las cosas que seguían teniendo algunos autores españoles ya bien avanzada la década de los ochenta como lo demuestra la cita de Gómez de las Roces que decía «el diputado y el senador no disponen, desde luego, de mecanismo formal alguno que les ampare en caso de discrepancia con los órganos de la Cámara, para el ejercicio de las facultades individuales que tenga reconocidas...el parlamentario puede suplicar, protestar o reiterar su iniciativa pero no puede recurrir el acuerdo denegatorio» ${ }^{21 .}$

En otros países, como Alemania, la solución es relativamente compleja. No se les reconocen verdaderos derechos a los parlamentarios pero estos pueden defender sus "competencias" a través del mecanismo del conflicto constitucional intraórganos ${ }^{22}$, configurándose asi una garantía de que los que dominen el Parlamento no podrán desconocer la posición jurídica de los minoritarios ${ }^{23}$.

La situación española es diferente. Por un lado los mecanismos informales de protección no se han desarrollado especialmente, debido a una falta de tradiciones parlamentarias provocada por las conocidas discontinuidad y precariedad en la existencia de nuestra instituciones representativas, que, además, ahora no son sólo las centrales del Estado, sino que se consolidan en todas las Comunidades Autónomas, con el consiguiente aumento de las posibilidades de controversia. Por otro, la manera en que se han configurado las competencias del Tribu-

21 "Las facultades parıamentarias de ejercicio individual", en AA.VV., Las Cortes Generales, vol. II, Madrid, 1987, p. 1286.

22 Art 93.1.1, LFB: "La Corte Constitucioanl Federal decide: sobre la interpretación del la presente Ley Fundamental respecto a controversias sobre el alcance de los derechos y deberes de un órgano supremo de la Federación o de otras partes investidas de derechos propios por la presente Ley Fundamental, o por el reglamento interno de un órgano federal supremo". Sobre el mismo puede ver K. SCHLAICH, Das Bundesverfassungsgericht, he manejado la segunda edición revisada, Munich, 1991. El problema en las pp. 51 y ss.

23 En la doctrina, aparte de Schreiner en op. cit. en nota 9, ver KLeIN, "Status des Abgeordneten", en ISENSEE/KIRCHHOF (Hg.), Handbuch des Staatsrechts, tomo II, Heidelberg, 1987, p. 388; AcHTERBERG, Parlamentsrecht, Tubinga, 1984, p. 777; y BADURA, "Die Stellung des Abgeordneten nach dem Grundgesetz...", en SCHNEIDER 'Y ZEH (Hg.), op. cit. en nota 9, p. 514, que niegan todos la posibilidad de ir a un recurso de amparo por violación del status del parlamentario. 
nal Constitucional, especialmente en el terreno del conflicto entre órganos constitucionales, excluyendo el que pudiera desarrollarse dentro de ellos, y en el del recurso de amparo, con la previsión del art. 42 LOTC, ha hecho que los problemas mayorías-minorías se hayan canalizado por esta última vía, vía en la que es necesario alegar que se está violando un verdadero derecho fundamental, por lo que o las facultades de los parlamentarios se construyen como tales o es imposible hacerlas valer ante órganos jurídicos externos a las Cámaras. Es probablemente este último hecho el que ha impulsado a los recurrentes $y$, en algunos casos, al Tribunal Constitucional a adscribirse a la idea de que existen derechos fundamentales dentro del Parlamento, quizás porque ésta sea la única manera en nuestro sistema de proteger los aspectos más importantes de la posición de las minorías que pudieran quedar, de otro modo, desatendidas.

Pero hay que ser conscientes de que, como ha escrito Caamaño, la operación de convertir al miembro de las Asambles en titular de derechos fundamentales «introduce inevitablemente una nueva dinámica en las relaciones parlamentario/órgano " ${ }^{24}$. Es todo un mundo de posibilidades inexploradas, en las que no nos sirven de guía las experiencias extranjeras que discurren por otros derroteros, y que, sin embargo, constituye un acierto en el sentido de que responde a las necesidades de un sistema parlamentario -o varios sistemas, si tenemos en cuenta a las Comunidades Autónomas - como el nuestro en el que se plantean todos los dias problemas de protección de los grupos minoritarios que pueden resolverse adecuadamente, cuando sean de suficiente entidad, por la actuación de la justicia constitucional.

En este sentido cabe decir que afirmar que los miembros de las Cámaras tienen verdaderos derechos y que - aunque unos puedan ser defendidos perfectamente por los órganos de gobierno de aquéllas, puesto que los mismos debieran representar un importante papel en la tarea de proteger a la vez la posición de los grupos minoritarios y la autonomía de las Asambleas, autonomía que excluye en ciertos casos la intervención de instancias externas que nos llevaría a un indeseado judicialismo ${ }^{25}$ - hay algunos de éstos que deben considerarse derechos

24 El Mandato parlamentario, Madrid, 1991, p. 78. De este autor debe consultarse también su artículo "Mandato parlamantario $y$ derechos fundamentales (Notas para una teoría de la representación "constitucionalmente adecuada")", en Revista Española de Derecho constitucional, n. ${ }^{\circ} 36$ (1992), pp. 123 y ss.

25 Sobre los riesgos del judicialismo entendido como imperialismo excluyente advirtió con acierto en su momento A. Fernández-Miranda en el prólogo a 
fundamentales $y$, por tanto, susceptibles de protección por la vía del art. 42 LOTC. Creemos que ésta es una opción correcta, congruente con el tipo de Estado social y democrático de Derecho en el que actúan nuestros Parlamentos y más adecuada a la situación de éstos a fines del siglo $X X$, en sociedades fuertemente divididas y muy complejas en las que el derecho debe servir para que no se cierre en ningún caso la posibilidad de construir una convivencia difícil pero ciertamente enriquecedora.

Derechos, por tanto, de los parlamentarios y no meras facultades. Es necesario reinterpretar como consecuencia de ello muchas de las construcciones clásicas, porque no conviene olvidar que éstas respondían a una situación muy diversa y no hay razón para adherirse acríticamente a las mismas. Veamos ahora como se ha movido en esta línea nuestro Tribunal Constitucional y que problemas plantea su construcción.

\subsection{La construcción del Tribunal Constitucional. Problemas y alternativas}

La jurisprudencia del Tribunal Constitucional en materia de derechos fundamentales de los parlamentarios ha sido acertadamente calificada de "proteccionista", destacando que "ha puesto al parlamentario individual en una posición especialmente protegida frente al partido político, frente al Grupo Parlamentario y frente a los órganos de la propia Asamblea legislativa» ${ }^{26}$.

Sus primeros pasos tienen que ver, sin embargo, con problemas ajenos al Parlamento, y los da el Tribunal afirmando que "el derecho a acceder a los cargos y funciones públicas implica también, necesariamente, el de mantenerse en ellos y desempeñarlos de acuerdo con lo previsto en la Ley, que, como es evidente, no podrá regular el ejerccio de los cargos representativos en términos tales que se vacíe de conte-

I. Torres Muro, Los órganos de gobierno de las Cámaras legislativas, Madrid, 1987, p. 12. Ha de resaltarse sin embargo que las desconfianzas hacia la jurisdicción ordinaria le parecen a algún autor parte de uuna visión... por completo inconsistente con la realidad de nuestro Estado constitucional' (J. JIMÉNEz CAMPO, en op. cit. en nota 6, p. 227).

26 Antonio BAR CENDÓN, "Los Parlamentos autonómicos ante el Tribunal Constitucional", en F. PAU I VALL (coord.), op. cit. en nota 2, p. 145. 
nido la función que han de desempeñar, o se la estorbe o dificulte mediante obstáculos artificiales, o se coloque a ciertos representantes en condiciones inferiores a otros, pues si es necesario que el órgano representativo decida siempre en el sentido querido por la mayoría, no lo es menos que se ha de asignar a todos los votos igual valor y se ha de colocar a todos los votantes en iguales condiciones de acceso al conocimiento de los asuntos y de participación en los distintos estadios del proceso de decisión" (STC 32/1985, FJ 3.).

Esta interpretación del artículo 23 CE lo enriquecía notablemente pero no creemos que se pueda dudar de su congruencia con el mismo. El Tribunal extrae de aquél la idea de que para que pueda considerarse como verdaderamente efectivo ha de extender su protección al ius in officio, es decir al momento en el que el elegido pretende ejercer sus funciones en representación de sus electores. De otro modo toda la construcción de dicha norma se convertiria en una cáscara vacía sin ningún efecto práctico o, al menos, con efectos muy limitados.

El siguiente hito en la jurisprudencia del Tribunal, el decisivo, es la sentencia que aplica esta doctrina por primera vez al ámbito parlamentario: nos referimos a la 161/1988. En ella se dice, entre otras cosas, que «el derecho fundamental del art. 23.2 de la Constitución...es un derecho de configuración legal, como de forma inequívoca expresa el último inciso del precepto $y$, en su consecuencia, compete a la ley, comprensiva según se deja dicho, de los Reglamentos parlamentarios, el ordenar los derechos $y$ facultades que corresponden a los distintos cargos y funciones públicos. Una vez creados por las normas legales tales derechos y facultades, éstos quedan integrados en el status propio de cada cargo con la consecuencia de que podrán sus titulares, al amparo del art. 23.2 de la Constitución, defender ante los órganos judiciales $-y$ en último extremo ante este Tribunal- el ius in officium que consideren ilegítimamente constreñido o ignorado por actos del poder público, incluidos los provenientes del propio órgano en el que se integren los titulares del cargo, con la especialidad de que si el órgano es parlamentario la defensa del derecho deberá promoverse directamente ante esta jurisdicción constitucional en aplicación de lo dispuesto en el art. 42 de la LOTC" (FJ $7 .^{\circ}$ ).

La operación es sumamente trascendente desde el momento en que, como se ha dicho, parece que "lo que son las reglas básicas del principio democrático y del pluralismo político (la regla de la mayoría, el voto igual, la libre participación de todos en la formación de la voluntad del órgano), concebidas como facultades individuales del repre- 
sentante, han sido reformuladas por el Tribunal como derechos fundamentales protegidos por el art. 23.2 CE»27.

Entra así éste a controlar la vida de las instituciones representativas evitando que se convierta en una farsa y protegiendo a las minorías que ven abierta la posibilidad de que una instancia externa revise los actos de las Cámaras y de sus órganos que puedan suponer menoscabo de su posición en las mismas.

La combinación de 23.2 CE y 42 LOTC resulta, por tanto, muy importante en la tarea de impedir los posibles abusos de los grupos mayoritarios y mantener abiertas las posibilidades de debate libre imprescindibles en toda sociedad democrática. Sólo cabe, por ello, felicitarse por el hecho de que el Tribunal la haya visto clara y la eleve a clave de bóveda de su manera de entender el problema.

Sentencias y autos posteriores han venido a matizar esta toma de posición, pero sin apartarse de sus líneas fundamentales. Por un lado el Tribunal ha confirmado la conexión entre los dos apartados del art. 23 en varias de sus decisiones, de las que se puede citar, por ser la más rotunda y la que supone una aplicación de esta doctrina al ámbito propiamente parlamentario, la STC $205 / 1990$ en cuyo fundamento jurídico $4 .^{\circ}$ se dice que "no es ocioso recordar que este Tribunal ha interpretado en distintas ocasiones que la norma contenida en el art. 23.1 de la Constitución, relativa al derecho a participar en los asuntos públicos, resulta indisolublmente unida de la prevenida en el apartado $2 .^{\circ}$ del mismo precepto, derecho a acceder en condiciones de igualdad a las funciones y cargos públicos con los requisitos que señalan las leyes, cuando se trata de una pretensión deducida por cargos públicos o representantes parlamentarios y en el ejercicio de sus funciones...sin perjuicio de que sea el apartado $2 .^{\circ}$ aquel que se encuentra más directamente afectado cuando de preservar los derechos de los representantes en el ejercicio de sus funciones se trata"; $y$ en el fundamento $5^{\circ}$ remacha el Tribunal, afirmando que "el derecho fundamental del art. 23.2 garantiza no sólo el acceso en condiciones de igualdad a los cargos públicos sino también que los que hayan accedido a los mismos se mantengan en elllos sin perturbaciones ilegítimas y puedan desempenarlos de conformidad con lo que la ley disponga... pues, de no ser así,

27 Cano Bueso, en op. cit. en nota 19, p. 70. En la bibliografía de este libro se contiene una orientación sobre los muchos comentarios que se han hecho a esta sentencia y que es imposible citar aquí. Quizás el más reciente sea el de MANCISIDOR, citado en la nota 2. 
la norma constitucional quedaría privada de toda eficacia $y$, por otra parte, porque la defensa de este derecho comporta la garantía del derecho mismo de los ciudadanos a participar a través de sus representantes en los asuntos públicos, reconocido en el art. 23.1».

Como ha escrito Martín, de esta construcción se deduce que «los representantes son los sujetos activos a cuyo través se manifiesta el orden democrático de la comunidad. De esta manera, si se priva a un cargo representativo de ejercer las funciones que la Ley o el Reglamento parlamentario le ha conferido, se vacía de contenido el cargo $y$, consecuentemente, se deja sin efecto la propia representación produciéndose una lesión del orden democrático establecido en la Constitución ${ }^{28}$.

Por otra parte el Tribunal Constitucional ha dado muestras de un cierto autocontrol a la hora de entrar en la vida de las Cámaras que se ejemplifica en algunos autos ya antiguos, como el 292/1987 o el 252/ 198929; en sentencias como la 36/1990 en la que se afirma que "no toda infracción de los Reglamentos de las Cámaras, per se, constituye una violación de derechos fundamentales susceptibles de tutela mediante el recurso de amparo de no redundar en una lesión constitucional; por consiguiente, no es correcto incluir la generalidad de las normas de los Reglamentos parlamentarios...en el bloque de la constitucionalidad relativo al art. 23 de la Constitución" (FJ 2. ${ }^{\circ}$; y en autos ya más recientes, como el 42/1997, en el que renuncia a juzgar una interpretación reglamentaria de los órganos rectores ya que "la intervención judicial ha de reducirse al mínimo imprescindible" y porque, dada la razonabilidad de aquélla, "resultaría claramente excesivo un pronunciamiento de este Tribunal contrario al criterio" de los mismos.

Pero quizás la sentencia más importante sobre estos asuntos sea la 220/1991 en la que intenta delimitar el alcance de su doctrina afirmando que "no supone constitucionalizar todos los derechos y facultades que constituyen el Estatuto del parlamentario, sino tan sólo aquéllos que pudiéramos considerar pertenecientes al núcleo esencial de la función representativa parlamentaria, como son, principalmente, los que tienen relación directa con el ejercicio de las potestades legis-

28 Esther Martín Núñez, op. cit. en nota 1, p. 126.

${ }_{29}$ Este último no publicado, sino reseñado en el repertorio Juriprudencia Constitucional. Tenemos conocimiento del mismo gracias a M. PuLIDo Quecedo, que hace una referencia en su libro El acceso a los cargos y funciones públicas. Un estudio del art 23.2 de la Constitución, Madrid, 1992, p. 323. 
lativas y de control de la acción del Gobierno" (FJ 5.`). Para Biglino el Tribunal en la misma «no soluciona el problema. Al contrario, puede afirmarse que constituye una manifestación de su existencia como tal problema. Así resulta difícil imaginar una sola facultad reconocida a los parlamentarios que no esté relacionada con dichas funciones ${ }^{30}$. Algo hay de cierto en ello y este no es sino uno de los varios flecos que presenta la construcción jurisprudencial a la que nos hemos venido refiriendo, flecos que intentaremos analizar a continuación.

El primero de ellos tiene que ver con la definición de este derecho como uno de configuración legal. Es cierto que el art. 23.2 habla de "los requisitos que señalen las leyes" pero también lo es que la idea del Tribunal, a la que ya se hizo referencia, de que sean éstas y los Reglamentos parlamentarios las que determinen cúal es el contenido del derecho, esa construcción que supone que, como ha dicho gráficamente Aguiar, "el ius in officium del artículo 23 es de textura totalmente abierta ${ }^{31}$, presenta problemas agudamente planteados por Garcia Roca para quien «el dato de que un Reglamento parlamentario conceda o excluya ciertas potestades o atribuciones a un representante no es razón bastante para pensar que, desde ese momento, sea o deje de ser a la vez un derecho de rango constitucional" y "no puede volver a incurrirse en el error de interpretar la Constitución a la luz de los Reglamentos de las Cámaras. Las facultades e intereses que integran el contenido del derecho fundamental deben extraerse directamente de la Constitución y de la observación del Estado constitucional» ${ }^{32}$. Coincidimos con este autor. Es verdad que el Tribunal no se niega al juego del contenido esencial del art. 53.1 CE, que limitaría las posibilidades del "legislador-reglamentador» de desfigurar el derecho, pero también lo es que quizás hubiera podido ser más explícito en la delimitación del contenido del mismo ligándolo a principios constitucionales como, por ejemplo, el del pluralismo (art. 1.1 CE), y que dejar en manos de los habilitados para rellenar las vaguedades constitucionales prácticamente todo lo que ha de entenderse por derecho a ejercer el cargo representativo es una operación arriesgada. Quizá la única que podía hacerse, dado que la función del Tribunal no es construir teorias sino responder a los casos concretos que se le plantean, pero, en todo caso, con aspectos insatisfactorios.

30 En op. cit. en nota 10, p. 78.

31 "La composición y organización parlamentarias en la jurisprudencia constitucional", en F. PAU I VALL (coord.), op. cit. en nota 2, p. 63.

32 Op. cit. en nota 16, p. 93. 
Consecuencia de esto, como se ha señalado, es la «notable extensión -con límites hoy inciertos - de ese control constitucional sobre la actuación interna de las Cámaras» ${ }^{33}$. Puede ser que lo de los límites inciertos, que no se construyan de una vez por todas, sea un dato dificil de superar si no se quiere encorsetar a la jurisprudencia constitucional, que es conveniente que progrese a golpe de caso, respondiendo a problemas concretos; pero también es verdad que hay un cierto grado de endeblez en el entramado construido a partir del art. 23.2 y en torno a los derechos de los parlamentarios, endeblez que el Tribunal debería ir superando poco a poco al hilo del planteamiento y resolución de los múltiples problemas que todos los años se le presentan al respecto.

En otro orden de cosas también hay que resaltar el peligro claro de que se intente involucrar al Tribunal Constitucional en cuestiones de índole meramente política. Como señaló acertadamente en su momento Cobreros «no es descartable...que los debates políticos, cuya sede privilegiada es el Parlamento, intenten proseguirse fuera del mismo sub specie iuris, de tal manera que lo primariamente perseguido con ello no es tanto la aplicación de las normas jurídicas cuanto el hecho mismo de que la controversia siga viva...los perniciosos efectos de una eventual práctica continuada esta "estrategia" política resultan bsatante evidentes... Al Tribunal Constitucional habrá de acudirse solamente cuando no hayan sido respetados $-y$ de manera constitucionalmente relevante - los derechos de participación y no cuando, simplemente, no se haya obtenido el resultado deseado ${ }^{34}$.

Algo de esto sabe ya el órgano al que nos referimos y parece que poco puede hacerse para evitar el problema sino recomendar el uso ponderado de la facultad de recurrir al mismo por parte de los legitimados para ello. También es cierto que se trata de presiones no muy difícilmente resistibles siempre que se cuente con un cuerpo jurisprudencial claro que delimite con precisión cuando nos hallamos ante un verdadero debate jurídico y cuando no. Forman parte del pan nuestro de cada día para un órgano de justicia constitucional y debe acostumbrarse a convivir con ellas siendo, eso sí, firme en su posición de evitarlas en lo posible.

33 J. JimÉnez CAMPo, en op. cit. en nota 6, p. 221.

34 "El "status" del parlamentario como derecho fundamental garantizado por el artículo 23.2 de la Constitución", en AA.VV., Estudios sobre la Constitución española. Homenaje al profesor Eduardo García de Enterría, tomo III, Madrid, 1991, p. 2153. 
Es conveniente, para finalizar este análisis de los aspectos generales de la construcción del Tribunal, decir que han surgido alternativas teóricas a la misma que tienen interés desde el momento en que se mueven también en la idea de que existen derechos fundamentales de los parlamentarios pero intentan superar los problemas que plantea aquélla. Nos referimos a las sugerencias que hace Jiménez Campo en el sentido de que: el art. 23.2 no enuncia un derecho de configuración legal, sino de igualdad... la defensa del status del representante, de sus facultades $y$ atribuciones, no tiene otro entronque con el orden de los derechos fundamentales que el que deriva, sin otras conexiones o adherencias, de lo enunciado en el artículo $23,1 \ldots$ y son la igualdad en el ejercicio de un derecho de contenido esencial reconocible las dos exigencias que la Constitución impone al poder público.

De ello, y de la idea de que el derecho fundamental se reconoce en el seno de una garantía institucional - la representación políticadeduce el autor que "el acto parlamentario que incide, de modo singular, en las facultades y atribuciones del representante o del grupo sólo podrá ser fiscalizado en amparo en dos hipótesis. La primera...es la de que se impute a tal acto un entendimiento de lo que la representación sea absolutamente inconciliable con lo exigido por su garantía institucional... la segunda... es la de que la resolución parlamentaria constriña o limite las facultades del representante o del grupo con quiebra immotivada de los propios precedentes ${ }^{36}$.

Aceptar estas tesis supondría quizás dotar de mayor precisión a la jurisprudencia constitucional que se ha ido construyendo, como ya tuvimos ocasión de decir, en respuesta a la rica casuística planteada $y$, por ello, con unos límites no demasiado claros. También es posible que llevara al Tribunal a fundamentar adecuadamente un ejercicio de autocontrol que puede juzgarse como necesario por algunos. Sin descartar su indudable rigor teórico parece ya de difícil aplicación dado todo el camino recorrido hasta el momento, camino en el que pueden haberse cometido excesos pero en el que, en general, cabe decir que se ha respondido con acierto a los dilemas planteados. Al análisis de cuáles han sido estos asuntos en concreto dedicaremos el siguiente epigrafe.

lbidem, p. 230. 


\subsection{Las facultades que ha reconocido el Tribunal como derechos fundamentales}

No tendría sentido aquí hacer una relación exhaustiva de las sentencias en las que se han ventilado problemas en relación con el art. 23 CE y el derecho parlamentario porque ello nos ocuparía sin duda mucho espacio ${ }^{37}$ pero sí podemos referirnos a las más importantes, aquellas que han venido a blindar algunas de las facultades de los diputados y senadores considerándolas como derechos fundamentales, y poniendo límites a los poderes de las mayorías que éstas suelen ejercer a través de los órganos de gobierno de las Cámaras.

Ya sabemos que hay decisiones en las que se resalta que no todas las facultades reconocidas en los Reglamentos son derechos de este tipo y que la que abrió camino en el reconocimiento de uno de ellos, el que tienen los parlamentarios a la información, fue la tantas veces citada, y repetidamente comentada, 161/1998, que vendria a complementarse por la 181/1989. Hay otros pronunciamientos sobre el tema, como las SSTC 196/1990 y 220/1991 y el auto $426 / 1990$, que han sido considerados como "restrictivos» ${ }^{38}$ pero que no niegan, aunque si maticen, el reconocimiento de dicho derecho. Los parlamentarios españoles tienen por tanto reconocido, como parte de su status protegido por el art. 23.2 CE, un derecho a solicitar la información necesaria para el cumplimiento de sus funciones.

Otro terreno en el que el Tribunal ha decidido varias veces es en el de las emmiendas. Para Redondo, que intenta superar la falta de un pronunciamiento taxativo del mismo, "parece indudable que la facultad de presentar enmiendas y el consiguiente derecho a defenderlas en las sedes que corresponda... constituye una facultad esencial que incorpora el mandato parlamentario, entrando a formar parte del contenido mínimo del derecho garantizado ex artículo 53.1 en relación con el $23 »^{39}$.

37 Puede remitirse a dos recientes relaciones de jurisprudencia constitucional en materia parlamentaria. La publicada por F. PAU I VALL y otros en op. cit. en nota 2, pp. 613 y ss., y la que han añadido J. M. Morales Arroyo y M. J. Terol Becerra a su cuidada edición del Reglamento del Parlamento de Andalucía, Sevilla, 1997, pp. 239 y ss. Es también útil, y ejemplo de a qué extensión nos podría llevar la mera referencia a todas las sentencias, el libro de LUIS DE LA PEÑA Derecho parlamentario español y Tribunal Constitucional, Granada, 1998, que tiene 522 páginas.

38 Mancisidor, en op. cit. en nota 2, p. 349. Allí remitimos, al igual que al libro de Cano Bueso, op. cit. en nota 19, para mayores desarrollos.

39 "La facultad de presentar enmiendas como concreción del derecho fundamental reconocido en el artículo 23.2 de la Constitución", en F. PAU I VALL (coord.), op. cit. en nota 2 , p. 385 . 
La jurisprudencia sobre el tema es variada y va desde la STC 23/1990 a la 118/1995, por citar las más importantes. En ambas se reconoce, con matices en los que no podemos entrar ${ }^{40}$, el derecho a presentar enmiendas y a que éstas sean admitidas a trámite siempre que cumplan las condiciones reglamentarias y se atengan a la regla de la congruencia con el proyecto.

La admisión de mociones es el siguiente tema que trata en Tribunal, principalmente en sus sentencias 205/1990 y 41/1995 y el auto 155/1993. Las contradicciones de esta jurisprudencia han sido acertadamente comentadas por Arce ${ }^{41}$ puesto que si en un principio parecía que se limitaban al máximo las facultades de las Mesas, configurando una especie de derecho - un ius ut procedatur- a que se tramitaran las iniciativas que no fueran abiertamente contrarias a la normativa vigente y excluyendo juicios de oportunidad, más adelante, si bien en base a otro reglamento - efecto perverso de la "textura abierta" del 23.2 CE de la que ya hablamos - se convalida uno de este último tipo.

En el caso de las proposiciones de ley tanbién existen pronunciamientos divergentes en las sentencias 95/1994 y 124/199542, aunque en ambos casos se reconozca un derecho a la admisión de las mismas. En la primera parece convalidarse la posibilidad de rechazarlas cuando resulte evidente su inconstitucionalidad material o competencial (FJ $\left.5 .^{\circ}\right)$ mientras que en la segunda ésta se niega expresamente (FJ $4 .{ }^{\circ}$ ). Lo importante, sin embargo a nuestros efectos es que el Tribunal declara que "la indebida inadmisión a trámite de una proposición de ley no es...una mera infracción del Reglamento constitucionalmente irrelevante. Antes bien, esa denegación injustificada afecta al núcleo mismo de la representación, pues al impedirse a los parlamentarios proponentes el lícito ejercicio de su derecho de iniciativa como parte de su ius in officium...y con vulneración, por tanto, del art. 23.2 de la Constitución, también se vulnera el derecho de los ciudadanos a verse representados y a participar indirectamente en los asuntos públicos (ex art. 23.1 CE)..." (124/1995, FJ 3..$^{\circ}$. Se configura así un nuevo derecho de los diputados, el de que sus proposiciones de ley sean tramitadas convenientemente $y$ sin trabas.

$40 \quad Y$ para los cuales la acertadas síntesis, que incorporan trabajos anteriores, de DE LA PEÑA, op. cit. en nota 37, pp. 366 y ss., y de A. ARCE, «¿Overruling en la jurisprudencia constitucional sobre el trámite parlamentario de admisión?», en F. PAU I VALL (coord.), op. cit. en nota 2, pp. 374 y ss.

41 En op. cit. en nota 40 , pp. 369 y ss.

42 De nuevo cabe remitir a ARCE, op. cit. en nota 40, pp. 371 y ss 
Por lo que respecta a la función de control de las Cámaras el Tribunal Constitucional se ha ocupado de las interpelaciones en el auto $614 / 1988^{43}$ y en la sentencia 225/1992. Criticando la doctrina sostenida en el primero en el sentido de que la no admisión no afectaba a los derechos del parlamentario, afirmó Pulido en su momento que «el derecho a interpelar forma parte del status del cargo representativo en cuanto manifestación de una actuación de control políticon ${ }^{44}$, que es la idea que puede deducirse de la sentencia, aun cuando en ésta también se convalide el acto de la Mesa de no admitir a trámite.

La participación en Comisiones fue enjuiciada en la STC 214/1990 que vino a reconocer que todos los diputados tenían derecho a formar parte de, al menos, una de ellas. Hay otras sentencias sobre el tema -ver, por todas, la reciente 93/1998- pero se refieren más a problemas de proporcionalidad que a los de derechos de los parlamentarios ${ }^{45}$.

De otra decisión del Tribunal Constitucional -la STC 81/1991puede deducirse la existencia de un derecho a forzar la convocatoria del Pleno de la Cámara cuando se cumplan los requisitos reglamentarios, que se deriva de las afirmaciones hechas en su FJ $3 .^{\circ}$ cuando se dice que la Mesa no debiera poder impedir «el ejercicio de una facultad propia del cargo, como lo es la presentación al Pleno de una propuesta...". Para Pulido de esta sentencia da a entender que "la no tramitación de una propuesta de un Grupo parlamentario formalizada con arreglo a lo que establece el Reglamento, vulnera el artículo 23,2 CE y, por ende, menoscaba el status del representante ${ }^{46}$.

Acaban aquí las alusiones a la jurisprudencia constitucional ${ }^{47}$ no sin antes advertir que en las mismas se han mezclado las facultades de ejercicio individual de los parlamentarios con aquéllas para las que les es necesario el concurso de otros, o que se atribuyen a los Grupos. Por eso quizás convenga ahora verificar un repaso a los reglamentos $y$ otras normas que regulan su posición, haciéndolo desde esta nueva perspectiva; es decir, preguntándonos cuáles son al fin y al cabo los de-

43 Auto no publicado que conocemos gracias a PuLIDo, op. cit. en nota $29, \mathrm{p}$. 326, y a DE LA PEÑA, op. cit. en nota 37, pp. 421 y ss.

44 Op. cit. en nota 29, p. 326.

45 Al interesado en profundizar puede remitírsele a los artículos de AguIAR de Luque y F. Navas Castillo en F. Pau i Vall (coord.), op. cit. en nota 2.

46 Op. cit. en nota 29, p. 319.

47 Como conclusión puede remitirse a la acertada síntesis que hace E. MARTín en op. cit. en nota 1, p. 122. 
rechos de senadores y diputados, derechos que si pueden conectarse con el 23.2 CE han de defenderse por la vía del amparo y si no quedan encomendados a los órganos de gobierno, en una labor cuya importancia siempre es necesario destacar.

\section{UN REPASO A LOS REGLAMENTOS}

Las normas que regulan los derechos de los parlamentarios son los Reglamentos de las Cámaras, con alguna excepción aislada como los artículos 26.3 del Estatuto de Autonomia de Asturias y 25.3 del de Murcia que disponen que los diputados regionales «tienen derecho a formular preguntas, interpelaciones y mociones en los términos que el Reglamento determine. También les asiste el derecho a obtener de las autoridades públicas la información precisa para el desarrollo de sus funciones, salvo que se trate de actuaciones o materias en que el funcionario se halle obligado por ley a guardar secreto".

Del estudio de aquéllos respecto a la posición del diputado o senador de a pie se han sacado, en perspectiva comparada, conclusiones ciertamente descorazonadoras. Asi, Sánchez Navarro, tras realizar una investigación en la que incluye a Italia, Gran Bretaña y Portugal, afirma que el ordenamiento español se caracteriza por «la exclusión prácticamente total del parlamentario individual como sujeto activo en la vida de las Cámaras, provocando una drástica reducción del nivel de participación en las mismas» ${ }^{48}$.

Cualquier observador de nuestra vida política podria confirmar en un análisis no jurídico estas impresiones y el estudio de las normas desde luego no las desmiente, pero ello no nos releva de la obligación de dar un repaso a las mismas intentando sistematizarlas, cosa que haremos basándonos principalmente en los reglamentos del Congreso y Senado, pero con algunas referencias a los autonómicos que, por otra parte, suelen ser bastante miméticos con respecto a aquéllos.

Un primer bloque de derechos serían los elementales de participación en las tareas de la Cámaras como el de asistir con voto a las sesiones del Pleno y de las Comisiones de que formen parte (art. 6,1 Reglamento del Congreso -en adelante, RC), asistir sin voto a las 
Comisiones de que no formen parte (art. 6.1 RC) y formar parte al menos de una Comisión (art. $6.2 \mathrm{RC}$ ), algo que en Cataluña se configura también como un deber (art. 5 Reglamento del Parlamento de Cataluña -en adelante, RCat - ).

Destaca por otro lado el "derecho estrella", reconocido en casi todos los Reglamentos, a recabar datos de las Administraciones Públicas (art. 7 RC), que se complementa en algunos con el de recibir información y documentación de los servicios parlamentarios (art. 7.4 del Reglamento del Parlamento de Andalucía -en adelante RPA-).

Junto a determinados tratamientos (para los senadores el de excelencia; art. 23.1 del Reglamento del Senado- en adelante RS) incluyen todas las normas referencias a los derechos económicos: asignación (art. $8 \mathrm{RC}$ ), viajes (art. $24.1 \mathrm{RS}$ ), y cotizaciones a la Seguridad Social y a las Mutualidades (art. 9 RC).

Se reconoce siempre el derecho a constituir un grupo parlamentario (por ejemplo art. 20.1 RPA) y también a asociarse a uno (art. 24.3 RC).

La facultad de solicitar la reconsideración de los acuerdos de la Mesa es otra de las típicas (por ejemplo, art. 36,2 RS).

Dentro de los debates los parlamentarios ven reconocidos sus derechos a recibir previamente la documentación (art. $69 \mathrm{RC}$ ), hacer uso de la palabra cuando les corresponda(art. 84.1 RS), cederse el turno (art. 70,4 RC), pedir la observancia del Reglamento (art. $90 \mathrm{RS}$ ) o la lectura de normas o documentos (art. 79.2 RPA), replicar (art. 87 RS) e intervenir por alusiones (art. 71.1 RC).

Pueden también consultar las actas taquigráficas (art. 96.2 RC) y conocer actas y documentos (art. 25 RS).

En el marco de los procedimientos de creación de normas pueden los parlamentarios en el Senado defender propuestas de veto (art. $121 \mathrm{RS}$ ) o formular votos particulares (art. $117 \mathrm{RS}$ ); y, en todas las Cámaras, presentar enmiendas - con el conocimiento del portavoz del Grupo (art. 110.1 RC) -, proposiciones de ley - junto a otros miembros (art. 126.1 RC) -, formular objeciones al uso de la delegación legislativa (art. 153.2 RC) y propuestas en el proceso de autorización de tratados (art. 144 RS).

Por fin en los de control se les reconocen los derechos a hacer interpelaciones (art. $180 \mathrm{RC}$ ) y preguntas (art. $160 \mathrm{RS}$ ) y en algunos casos a presentar proposiciones no de ley con otros parlamentarios (por ejemplo art. 168 Reglamento murciano) o en solitario con conocimien- 
to del portavoz (art. 158 Reglamento de Castilla y León), facultad esta que en el Congreso está reservada a los Grupos (art. $193 \mathrm{RC}$ ). También pueden solicitar la intervención del Defensor del Pueblo (art. 200,2 RC).

Junto a este bloque de derechos se encuentran una serie de deberes que van desde el de asistencia ${ }^{49}$ (art. 20 RS), al de observar las normas sobre incompatibilidades (art. $19 \mathrm{RC}$ ) pasando por los de adecuar la conducta al reglamento y respetar el orden (por ejemplo, art. 14 RPA), el de secreto ${ }^{50}$ (art. 15 Reglamento de Aragón, entre otros muchos), el de no invocar su condición para el ejercicio de actividades (art. $17 \mathrm{RC}$ ) y el de formular una declaración de bienes patrimoniales (art. 18 $\mathrm{RC}$ ), que algunas veces se combina con la obligación de presentar copia de la declaración de la renta (art. 20 bis del Reglamento de Castilla la Mancha).

El balance que puede hacerse de este análisis es que, aunque parece evidente que los Parlamentos españoles son un ejemplo claro de "grupocracia», quedan resquicios para la actividad del parlamentario individual $y$ este tiene reconocidos una serie de derechos que le permiten, con limitaciones eso sí, cumplir con su función de representante en un ambiente en el que las posibles presiones de partidos no pueden ocultarse, pero en el que también hay posibilidades de ejercer responsablemente el mandato, posibilidades que deben ser protegidas por los órganos de gobierno $y$, en último caso, mediante el recurso al Tribunal Constitucional.

\section{CONCLUSIONES}

Para concluir puede decirse que en los veinte años de vigencia de la Constitución española se han asumido claramente, en este tema de los derechos de los parlamentarios, nuevas tendencias que vienen a intentar tomar nota de una situación en la que los miembros de las Cámaras deben estar protegidos adecuadamente frente a los embates de las mayorias.

49 Es interesante sobre este deber el artículo de Pablo DiEz LAGO, «El deber de asistencia de los parlamentarios a las sesiones y el derecho al ejercicio del cargo (art 23.2 CE)", Revista de las Cortes Generales, n. 23 (1991), pp. 28 y ss.

50 Sobre el cual puede verse el completo estudio de J. A. Alonso de ANTONio, "El deber de secreto de los parlamentarios", en Revista de la Facultad de Derecho de la Universidad Complutense, n. 76 (1990), pp. 3 y ss. 
En este contexto se enmarca la adecuada, aunque con algunos problemas, construcción jurisprudencial de nuestro Tribunal Constitucional, que puede calificarse en ciertos aspectos de revolucionaria, pero que responde con agudeza a problemas que hasta ahora no se habían planteado, y que necesitaban de soluciones imaginativas.

El balance ha de ser positivo teniendo en cuenta que, dado el tipo de parlamentarismo en el que nos encontramos, es necesario alcanzar el equilibrio entre una situación comprensible de dominio de la mayoría y el respeto a las posibilidades de los grupos minoritarios de construir alternativas. En esta perspectiva el reconocimiento de verdaderos derechos a los parlamantarios, protegibles por instancias independientes como los tribunales, es un acierto y un avance que permitirá seguir manteniendo bien abiertos los cauces de participación y crítica propios de una sociedad democrática.

Sólo cabe terminar haciendo votos porque, en el día a día, tanto el Tribunal Constitucional como el resto de los actores constitucionales continúen teniendo muy presentes estos objetivos. La salud del sistema saldrá ganando con ello. 